\title{
GBR 12909 administration as a mouse model of bipolar disorder mania: mimicking quantitative assessment of manic behavior
}

\author{
Jared W. Young • Andrew K. L. Goey • \\ Arpi Minassian • William Perry • Martin P. Paulus • \\ Mark A. Geyer
}

Received: 15 July 2009 /Accepted: 23 November 2009/Published online: 18 December 2009

(C) The Author(s) 2009. This article is published with open access at Springerlink.com

\begin{abstract}
Rationale Mania is a core feature of bipolar disorder (BD) that traditionally is assessed using rating scales. Studies using a new human behavioral pattern monitor (BPM) recently demonstrated that manic $\mathrm{BD}$ patients exhibit a specific profile of behavior that differs from schizophrenia and is characterized by increased motor activity, increased specific exploration, and perseverative locomotor patterns as assessed by spatial $d$.

Objectives It was hypothesized that disrupting dopaminergic homeostasis by inhibiting dopamine transporter (DAT) function would produce a BD mania-like phenotype in mice as assessed by the mouse BPM.

Methods We compared the spontaneous locomotor and exploratory behavior of $\mathrm{C} 57 \mathrm{BL} / 6 \mathrm{~J}$ mice treated with the catecholamine transporter inhibitor amphetamine or the selective DAT inhibitor GBR 12909 in the mouse BPM. We also assessed the duration of the effect of GBR 12909 by testing mice in the BPM for $3 \mathrm{~h}$ and its potential strain dependency by testing $129 / \mathrm{SvJ}$ mice.
\end{abstract}

J. W. Young $\cdot$ A. Minassian $\cdot$ W. Perry $\cdot$ M. P. Paulus $\cdot$

M. A. Geyer $(\bowtie)$

Department of Psychiatry, University of California, San Diego, 9500 Gilman Drive MC 0804,

La Jolla, CA 92093-0804, USA

e-mail: mgeyer@ucsd.edu

A. K. L. Goey

Utrecht University,

Sorbonnelaan 16 ,

3584 CA Utrecht, The Netherlands

M. P. Paulus

VA San Diego Healthcare System,

San Diego, CA, USA
Results Amphetamine produced hyperactivity and increased perseverative patterns of locomotion as reflected in reduced spatial $d$ values but reduced exploratory activity in contrast to the increased exploration observed in $\mathrm{BD}$ patients. GBR 12909 increased activity and reduced spatial $d$ in combination with increased exploratory behavior, irrespective of inbred strain. These effects persisted for at least $3 \mathrm{~h}$.

Conclusions Thus, selectively inhibiting the DAT produced a long-lasting cross-strain behavioral profile in mice that was consistent with that observed in manic BD patients. These findings support the use of selective DAT inhibition in animal models of the impaired dopaminergic homeostasis putatively involved in the pathophysiology of BD mania.

Keywords Bipolar disorder - Mania · Mouse model · Dopamine transporter Amphetamine · GBR 12909

\section{Introduction}

Bipolar disorder (BD) is a severe neuropsychiatric disorder, affecting approximately $1-2 \%$ of the population (Merikangas et al. 2007). Mania is the cardinal feature of BD and traditionally has been assessed using self- and observerrating scales. The qualitative nature of rating scales may contribute to the paucity of animal models for $\mathrm{BD}$ mania with most models being based on simple measures of motoric hyperactivity (Einat 2006b).

Motoric hyperactivity can be induced in rodents by manipulating numerous disparate neurotransmitter systems, yet these stimulants can be distinguished from one another by their differential effects on patterns of exploratory and 
locomotor behavior (Eilam and Golani 1989; File and Wardill 1975; Geyer 1990; Geyer and Paulus 1996; Geyer et al. 1986; Paulus and Geyer 1996; Szechtman et al. 1985). Traditionally, quantitative assessments of activity, exploration, and locomotor patterns have required the use of different testing chambers, such as the open field test, photobeam activity chambers, and holeboard tasks (Bushnell 1987; Collins et al. 1979; Fink and Smith 1979; Fitzgerald et al. 1988; Geyer et al. 1986; Gold et al. 1988; Gould et al. 2001; Kulkarni and Dandiya 1975; Meliska and Loke 1984; Paulus and Geyer 1992; Sessions et al. 1980). We developed the behavioral pattern monitor (BPM) for use in rats (Geyer et al. 1986; Paulus and Geyer 1993) and mice (Risbrough et al. 2006). The BPM combines aspects of each of these testing chambers, enabling quantitative multivariate assessments of activity, exploration, and locomotor patterns simultaneously. The BPM has proven to be effective in differentiating between diverse stimulants including amphetamine, apomorphine, caffeine, 3,4-methylenedioxy$\mathrm{N}$-methylamphetamine, nicotine, phencyclidine, and scopolamine (Geyer and Paulus 1996; Geyer et al. 1986; Paulus and Geyer 1993). The same principles of multivariate assessment used to differentiate stimulants in the BPM have recently been applied to quantifying the behavior of psychiatric inpatients in a human BPM, the development and conception of which is described elsewhere (Young et al. 2007b). As predicted, manic BD patients exhibit increased activity as measured by counts, distance traveled, and acceleration. BD patients also exhibit significantly more specific exploratory behavior than healthy comparison subjects as measured by object interactions. Moreover, the structure of the locomotor paths taken by BD patients differed from comparison subjects, with BD patients exhibiting reduced spatial $d$, indicative of distance covering as opposed to localized meandering exploration (Perry et al. 2009). Importantly, the exploratory profile of $\mathrm{BD}$ manic patients also differed considerably from that of schizophrenia patients, suggesting differing behavioral profiles dependent upon psychotic disorder (Perry et al. 2009). Hence, there exists a detailed quantitative assessment of behavior selective to $\mathrm{BD}$ inpatients, which animal models specific to BD mania should therefore also exhibit.

As discussed elsewhere (Geyer and Markou 2002), the identification of an animal model of a neuropsychiatric disorder can benefit both by comparisons with quantified behavioral characteristics seen in the disorder and by reference to the neural substrates that are hypothesized to underlie the abnormal behavior. A dysregulation of dopaminergic homeostasis may contribute to the $\mathrm{BD}$ mania profile (Manji et al. 2003; Vawter et al. 2000; Young et al. 1994). Abnormal expression of the dopamine transporter (DAT) has been implicated in the neuropathophysiology of
BD through genetic linkage studies (Greenwood et al. 2001, 2006; Kelsoe et al. 1996), with the functional consequences of an observed DAT mutation leading to reduced cell surface DAT expression (Horschitz et al. 2005). Amphetamine, which inhibits the DAT and other monoamine transporters (Han and $\mathrm{Gu}$ 2006; Rothman and Baumann 2006), is one of the most common animal models of BD in mice (Arban et al. 2005; Gould et al. 2001), rats (Cappeliez and Moore 1990; Frey et al. 2006; Shaldivin et al. 2001), and humans (Asghar et al. 2003; Silverstone et al. 1998). Despite the prevalent use of amphetamine as a model of BD, however, there has been limited success in developing therapies specifically for BD. Indeed, most current treatments were developed originally for other disorders and/or resulted from serendipitous observations (Cryan and Slattery 2007; Gould and Einat 2007). This poor treatment development rate may be due in part to the lack of pharmacological selectivity of the commonly used model, amphetamine. Amphetamine exhibits approximately a 5- to 9-fold greater affinity for the norepinephrine transporter (NET) than the DAT, with some efficacy at blocking serotonergic transporters also (Han and $\mathrm{Gu} 2006$ ). DAT knockdown (KD) mice on a 129/S background strain exhibit a selective $90 \%$ reduction in DAT expression (Zhuang et al. 2001). Recently, we demonstrated that DAT KD mice exhibit a phenotype in the mouse BPM that mimicked the profile of manic $\mathrm{BD}$ patients, increased activity and specific exploration with reduced spatial $d$ representative of greater distance covering behavior. In preliminary studies, acute administration of $2.5 \mathrm{mg} / \mathrm{kg}$ amphetamine to $\mathrm{C} 57 \mathrm{BL} / 6 \mathrm{~J}$ mice did not reproduce the manic BD phenotype as reduced specific exploration was observed (Perry et al. 2009). Acute administration of the DAT selective inhibitor GBR 12909 (Heikkila and Manzino 1984 ) at $16 \mathrm{mg} / \mathrm{kg}$, however, did produce a behavioral profile in C57BL/6J mice that was consistent with both BD mania patients and DAT KD mice (Perry et al. 2009). Thus, it appeared that GBR 12909 but not the "gold standard" mania model-amphetamine treatment-reproduced the BD mania exploratory phenotype in C57BL/6J mice.

Based on these initial findings, the present studies were designed to compare the full dose-response functions for the effects of amphetamine and GBR 12909 on exploratory behavior in $\mathrm{C} 57 \mathrm{BL} / 6 \mathrm{~J}$ mice assessed in the BPM. We also examine the time course of the effects of GBR 12909 over $3 \mathrm{~h}$. Finally, we examined the cross-strain consistency of effects of GBR 12909 by testing the same dose-response curve in $129 / \mathrm{SJ}$ mice in order to compare the drug-induced profile with the phenotype observed in DAT KD mice. We hypothesized that selective DAT inhibition produces a "mania-like" phenotype in mice that is independent of strain, long lasting, and not reproduced by any tested dose of amphetamine. 


\section{Materials and methods}

Animals

To assess the effects of amphetamine and GBR 12909, male C57BL/6J and $129 / \mathrm{SvJ}$ mice $(20-40 \mathrm{~g})$ were obtained from Jackson Laboratories and tested at approximately 4 months old. All mice were housed in groups of maximum four per cage with a reversed day-night cycle (lights on at 8.00 P.M., off at 8.00 A.M.) at the University of California, San Diego (UCSD) vivarium. The animals had unlimited access to water and food (Harlan, Madison, WI, USA) except during testing. Before testing, all mice were brought to the testing room covered against exposure to light for an acclimation period of at least $60 \mathrm{~min}$. Testing occurred between 9.00 A.M. and 6.00 P.M. All of the behavioral testing procedures were approved by the UCSD Institutional Animal Care and Use Committee. All mice were maintained in an animal facility that meets all federal and state requirements for animal care and was approved by the American Association for Accreditation of Laboratory Animal Care.

\section{Drugs}

$d$-Amphetamine sulfate (Sigma, St. Louis, MO, USA) was dissolved in saline and was administered with a $5-\mathrm{ml} / \mathrm{kg}$ injection volume. GBR 12909 dihydrochloride (Sigma, St. Louis, MO, USA) was dissolved in saline after sonicating for $2-4 \mathrm{~h}$ at $40^{\circ} \mathrm{C}$. Due to the poor solubility of GBR 12909 in saline, the injection volume was increased to $10 \mathrm{ml} / \mathrm{kg}$. Free-base drug weights were used in all drug calculations. All drugs were administered by intraperitoneal injection immediately prior to the mice being placed in the testing chambers and data recording initiated. Saline $(0.9 \%)$ was used as vehicle in each experiment. Drug doses were based on previous studies demonstrating increased activity and exploration following amphetamine (Gould et al. 2001, 2007; Arban et al. 2005) and GBR 12909 treatment (van den Buuse and de Jong 1989; Zalcman 2001).

\section{Mouse behavioral pattern monitor}

Spontaneous locomotor and exploratory behavior was examined in ten mouse BPM chambers as described previously (Risbrough et al. 2006). In brief, a single chamber consists of a $30.5 \times 61 \times 38-\mathrm{cm}$ area, with a Plexiglas hole board floor that was equipped with floor holes in the front, middle, and rear parts of the floor and eight wall holes (three along each side of the long walls and two holes in the front and back walls). Each hole is equipped with an infrared photobeam so holepoking behavior can be detected. The chamber is illuminated from a single light source above the arena (producing 350 lux in the center and 92 lux in the four corners). The location of the mouse is obtained from a grid of $12 \times 24$ infrared photobeams $1 \mathrm{~cm}$ above the floor $(2.5 \mathrm{~cm}$ apart along the length and the width of the chamber; 24_12 $X-Y$ array), recording the location of the mouse every $0.1 \mathrm{~s}$, with its position defined across nine unequal regions (four corners, four walls and center; Geyer et al. 1986). Rearing behavior is detected by an array of 16 infrared photobeams placed $2.5 \mathrm{~cm}$ above the floor and aligned with the long axis of the chamber. At the start of each test session, mice were placed in the bottom left-hand corner of the chamber, facing the corner, and the test session started immediately. The primary measures of interest were activity (transitions-movement across the defined regions), exploratory behavior (holepoking and rearing), and locomotor pattern (spatial $d$ ). Spatial $d$ quantifies the geometrical structure of the locomotor path, where a value of 2 represents highly circumscribed small-scale movements, while 1 represents straight-line distance-covering movements. To quantify spatial $d$, the path length of the animal is separated into micro-events based on successive $(x, y)$ coordinates to which different measuring resolutions $(k)$ are applied. Using a large $k$ corresponds to a more global depiction of movement while smaller $k$ values provide quantification of local events. Fitting a slope using a least-squares straight-line approximation between the logarithm of the values generated by these $k$ ranges provides the value for the spatial scaling exponent $d$ (Paulus and Geyer 1991).

Experiment 1: dose-response study on the effects of amphetamine on C57BL/6J mice in the mouse BPM

This study was conducted to determine a dose-response effect of amphetamine in C57BL/6J male mice administered vehicle $(n=6)$ or amphetamine at $0.5(n=7), 1.25$ $(n=7), 2.5(n=7), 5(n=7)$, or $10(n=7) \mathrm{mg} / \mathrm{kg}$. These mice had previously been exposed to the mouse BPM as well as an alpha 7 nicotinic acetylcholine receptor agonist and antagonists on two previous occasions, with $>8$ weeks washout period between studies. Some data from the mice treated with $2.5 \mathrm{mg} / \mathrm{kg}$ amphetamine were presented previously in Perry et al. (2009). The locomotor and behavioral activity of the mice was assessed for $60 \mathrm{~min}$ in the BPM.

Experiment 2: dose-response curve of GBR 12909—effects on $\mathrm{C} 57 \mathrm{BL} / 6 \mathrm{~J}$ mice in the mouse BPM

To establish the behavioral effects of GBR 12909 in the mouse BPM, a dose-response study was performed on C57BL/6J mice over $60 \mathrm{~min}$. Eighty male C57BL/6J mice were assessed in the BPM after acute administration of 
vehicle $(n=14)$ or GBR 12909 at $2.85(n=14), 5(n=13), 9$ $(n=13), 16(n=13)$, or $28.5 \mathrm{mg} / \mathrm{kg}(n=13)$. These mice had previously been exposed to the mouse BPM for characterization purposes one time over 10 weeks previously to current testing and were drug naïve. Some data from the mice treated with $16 \mathrm{mg} / \mathrm{kg}$ GBR 12909 were presented previously in Perry et al. (2009).

Experiment 3: dose-response curve of GBR 12909-effects on $129 / \mathrm{SvJ}$ mice in the mouse BPM

To assess putative strain-independent effects of GBR-12909 and to compare them with the phenotype of DAT-deficient mice on a mixed $129 / \mathrm{SvJ}-\mathrm{C} 57 \mathrm{BL} / 6$ background, a doseresponse study was performed in $129 / \mathrm{SvJ}$ mice over $60 \mathrm{~min}$. A total of 60 experimentally naïve mice were treated acutely immediately prior to testing in the mouse BPM with vehicle $(n=9)$ or GBR 12909 at $5(n=8), 9(n=8), 10.9$ $(n=9), 13.2(n=9), 16(n=9)$, or $28.5 \mathrm{mg} / \mathrm{kg}(n=8)$.

Experiment 4: duration of action of GBR 12909

in $\mathrm{C} 57 \mathrm{BL} / 6 \mathrm{~J}$ mice in the mouse BPM

To determine the duration of action of GBR 12909, a doseresponse study was performed in $\mathrm{C} 57 \mathrm{BL} / 6 \mathrm{~J}$ mice prior to a 3-h assessment of exploratory behavior in the mouse BPM. Experimentally, naïve mice were treated acutely with vehicle $(n=8)$ or $9(n=8), 16(n=8)$, or $28.5 \mathrm{mg} / \mathrm{kg}(n=8)$ GBR 12909.

\section{Statistics}

The data from each experiment were analyzed using a mixed analysis of variance, with treatment as a betweensubject variable and time as a within-subject variable. Significant main effects were analyzed using Tukey's post hoc analyses. The data were analyzed in 10- or 30-min time bins using the Biomedical Data Programs statistical software (Statistical Solutions Inc., Saugus, MA, USA). The alpha level was set to 0.05 .

\section{Results}

Experiment 1: amphetamine dose-response study

A dose-response curve of amphetamine was generated in male $\mathrm{C} 57 \mathrm{BL} / 6 \mathrm{~J}$ mice to assess the efficacy of amphetamine administration as a pharmacological model of bipolar disorder mania.

Locomotor activity A significant drug $\times$ time interaction was observed for transitions $(F(25,170)=6.15, p<0.0001$;
Fig. 1a), distance traveled $(F(25,170)=5.84, p<0.0001)$, and center entries $(F(25,170)=3.31, p<0.0001)$. Tukey's post hoc analysis revealed that mice treated with $5 \mathrm{mg} / \mathrm{kg}$ amphetamine exhibited significantly more transitions relative to vehicle $(p<0.05)$ at time period 1. Mice administered $2.5 \mathrm{mg} / \mathrm{kg}$ amphetamine exhibited significantly more transitions than vehicle-treated animals $(p<0.05)$ in time periods $2,3,4,5$, and 6 , while mice administered $10 \mathrm{mg} / \mathrm{kg}$ amphetamine exhibited significantly lower transitions in the same time periods $(p<0.05)$. A similar pattern was observed in distance traveled, with mice given $5 \mathrm{mg} / \mathrm{kg}$ amphetamine covering significantly greater distance than vehicle-treated mice in time periods 1 and 2 only $(p<0.05)$, while mice administered $2.5 \mathrm{mg} / \mathrm{kg}$ amphetamine exhibited greater distance traveled in every time period $(p<0.05)$. Mice administered $10 \mathrm{mg} / \mathrm{kg}$ amphetamine did not exhibit reduced distance traveled in any time period, likely due to floor effects $(p>0.05)$, but did exhibit lower center entries compared to vehicle control mice $(p<0.05)$ in time periods 2 and 5 .

Exploration Significant main effects of drug were observed for holepoking behavior $(F(5,34)=11.03, p<$ 0.0001 ; Fig. 1b) and time spent in the center $(F(5,34)=$ 2.64, $p<0.05$ ), while a significant drug $\times$ time interaction was observed for rearings $(F(25,170)=3.12, p<0.0001$; Fig. 1c). Post hoc analysis revealed a dose-response effect of amphetamine significantly lowering holepoking behavior, observed in mice administered 2.5, 5.0, and $10.0 \mathrm{mg} / \mathrm{kg}$ when compared to vehicle $(p<0.05)$, with a trend to lower holepoking behavior observed in $1.25 \mathrm{mg} /$ $\mathrm{kg}$ amphetamine-treated mice $(p<0.1)$. Post hoc analyses did not reveal any significant effect of any dose compared to vehicle in center entries or rearings at any time period $(p>0.05)$.

Locomotor pattern A significant drug $\times$ time interaction was observed for spatial $d(F(25,170)=4.56, p<0.0001$; Fig. 1d). Post hoc analyses indicated that mice administered $10 \mathrm{mg} / \mathrm{kg}$ amphetamine displayed higher spatial $d$ at time periods 3,4 , and 5 when compared to vehicle-treated mice $(p<0.05)$, further supporting a stereotypic effect at this dose. Mice administered $2.5 \mathrm{mg} / \mathrm{kg}$ amphetamine, however, displayed lower spatial $d$ when compared to vehicle controls $(p<0.05)$ although only at time period 1 .

Experiment 2: dose-response curve of GBR 12909—effects on $\mathrm{C} 57 \mathrm{BL} / 6 \mathrm{~J}$ mice in the mouse BPM

A dose-response study was performed with the selective DAT inhibitor GBR 12909 (vehicle, 2.85, 5, 9, 16, and $28.5 \mathrm{mg} / \mathrm{kg}$ ) in C57BL/6J mice. 


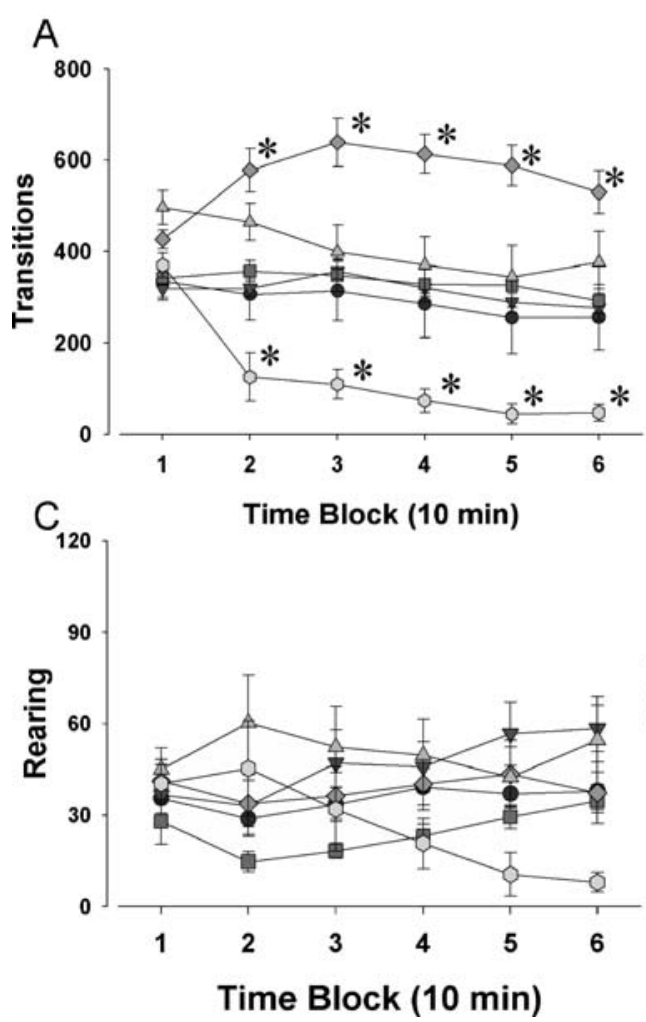

Fig. 1 Effects of amphetamine on exploratory behavior in C57BL/6J mice in the mouse BPM. The nonselective NET and DAT inhibitor amphetamine was administered to mice at various doses prior to their exploration in the mouse BPM. Exploratory behavior was measured as activity levels - transitions (a), specific exploration-holepokes (b) and rearing (c), as well as locomotor pattern-spatial $d$ (d). An inverted U-shaped dose-response was observed for amphetamine effects on activity where a low dose $(2.5 \mathrm{mg} / \mathrm{kg})$ increased activity

Locomotor activity Significant time $\times$ drug interactions were found for transitions $(F(25,340)=10.22, p<0.0001$; Fig. 2a), distance traveled $(F(25,340)=11.06, p<0.0001)$, and center entries $(F(25,340)=2.84, p<0.0001)$. Tukey's post hoc analyses for transitions revealed that mice administered 16 and $28.5 \mathrm{mg} / \mathrm{kg}$ of GBR 12909 exhibited higher levels of transitions $(p<0.05)$ than vehicle-treated mice in time periods 2 (16 mg/kg only), 3, 4, 5, and 6 . The analyses for distance traveled revealed that mice administered $16 \mathrm{mg} / \mathrm{kg}$ GBR 12909 exhibited higher levels of transitions $(p<0.05)$ than vehicle-treated mice in all time periods, while mice administered $28.5 \mathrm{mg} / \mathrm{kg}$ GBR 12909 differed from vehicle $(p<0.05)$ in time periods $2,3,4,5$, and 6 . For center entries, post hoc analyses revealed that mice administered 16 mg/kg GBR 12909 displayed higher levels of center entries than mice administered vehicle in time periods $2,3,4,5$, and $6(p<0.05)$.

Exploratory behavior Significant time $\times$ drug interactions were observed for holepoking $(F(25,340)=1.63, p<0.05$; Fig. 2b) and rearing $(F(25,340)=6.74, p<0.0001$; Fig. $2 c)$.
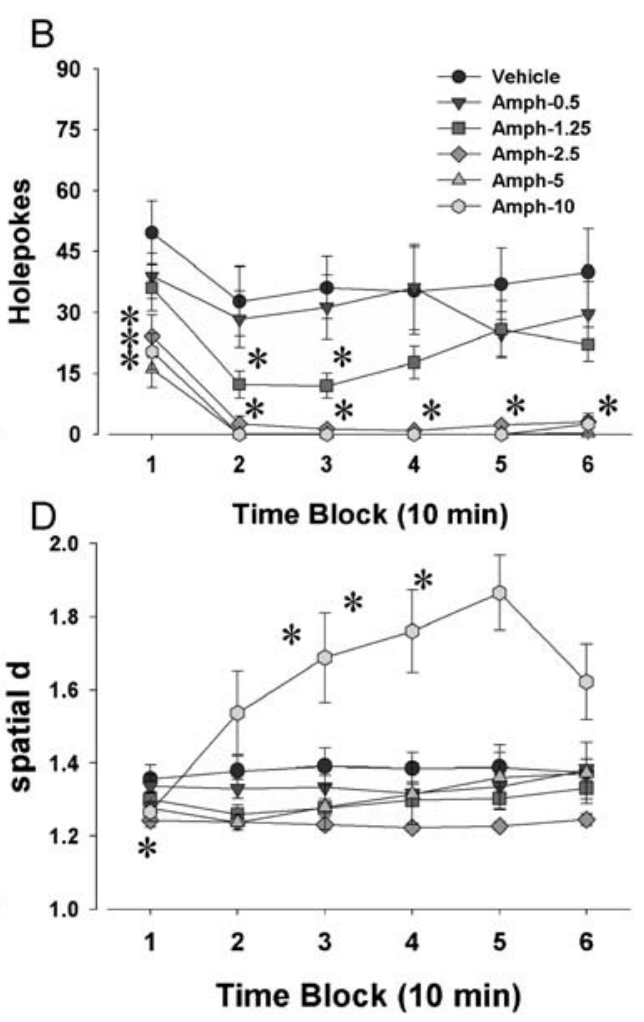

levels while higher dose $(10 \mathrm{mg} / \mathrm{kg})$ lowered activity levels (a). The only effect of amphetamine on specific exploration, however, was to reduce holepoking at all but the lowest dose (b), with no effect on rearing (c). Consistent with activity levels, there was a separation of effects between a low $(2.5 \mathrm{mg} / \mathrm{kg})$ and high $(10 \mathrm{mg} / \mathrm{kg})$ dose, with some reduction in spatial $d$ at low and increased spatial $d$ at high doses (d). Data presented as mean \pm SEM. ${ }^{*} p<0.05$ when compared to vehicle control

A nonsignificant trend effect of drug was observed for center duration $(F(5,68)=2.32, p=0.0521)$ but no significant time $\times$ drug interaction. Post hoc analyses for holepokes revealed that during time periods 2 and 3, mice administered $28.5 \mathrm{mg} / \mathrm{kg}$ of GBR 12909 showed lower levels of holepoking behavior than mice administered vehicle $(p<0.05)$. For rearing, mice administered $16 \mathrm{mg} / \mathrm{kg}$ GBR 12909 reared more than vehicle-treated mice in time periods $3,4,5$, and $6(p<0.05)$.

Locomotor patterns A significant time $\times$ drug interaction was observed for spatial $d(F(25,340)=3.61, p<0.0001$; Fig. 2d). Post hoc analyses revealed that mice administered 16 and $28.5 \mathrm{mg} / \mathrm{kg}$ GBR 12909 showed lower values of spatial $d$ than mice administered vehicle in time periods 3 , 4 , 5, and $6(p<0.05)$. Mice administered $5 \mathrm{mg} / \mathrm{kg}$ had significantly lower levels of spatial $d$ when compared to vehicle-treated mice in time periods 5 and $6(p<0.05)$, while mice administered 9 mg/kg GBR 12909 exhibited lower spatial $d$ values in time period 5 compared to vehicle $(p<0.05)$. 
Fig. 2 Effects of GBR 12909 on exploratory behavior in $\mathrm{C} 57 \mathrm{BL} / 6 \mathrm{~J}$ mice in the mouse BPM. Mice were administered various doses of the selective DAT inhibitor GBR 12909 prior to the assessment of their exploration in the mouse BPM. Exploration was measured in the BPM for activity levelstransitions (a), explorationholepoking (b) and rearing (c), as well as locomotor patternsspatial $d$ (d). GBR 12909 increased activity at the highest (16 and $28.5 \mathrm{mg} / \mathrm{kg}$ ) doses tested (a). The effects of GBR 12909 on exploration differed by dose and measure - the highest dose lowered holepoking (b) while the second highest dose increased rearing (c). Data presented as mean \pm SEM. $* p<0.05$ when compared to vehicle administered control mice

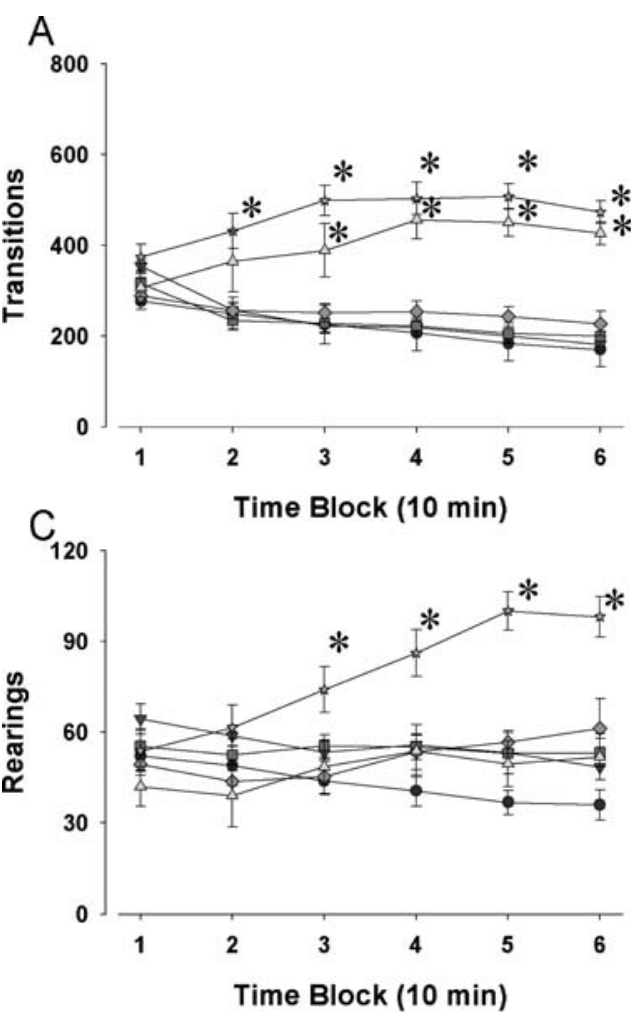

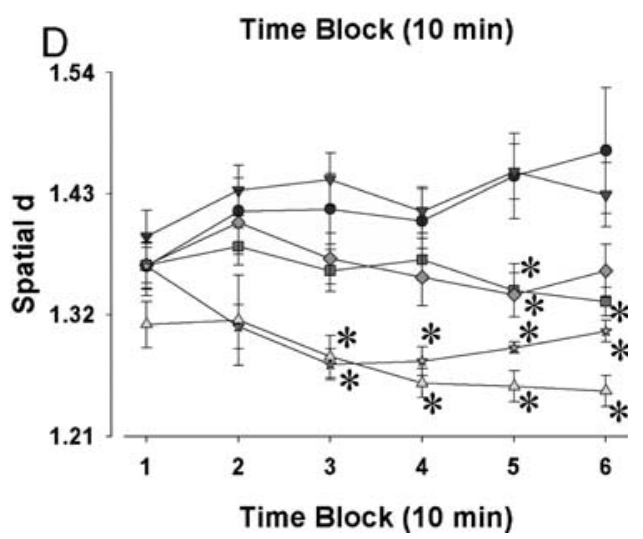

Experiment 3: dose-response curve of GBR 12909—effects on $129 / \mathrm{SvJ}$ mice in the mouse BPM

A dose-response study was performed with the selective DAT inhibitor GBR 12909 (vehicle, 5, 9, 10.9, 13.2, 16, and $28.5 \mathrm{mg} / \mathrm{kg}$ ) in $129 / \mathrm{SvJ}$ mice. We hypothesized that the effects of GBR 12909 would be similar to those seen in C57BL/6J mice and to the phenotype of the DAT-deficient mutant mice tested in the mouse BPM.

Locomotor activity Significant main effects of drug were found for transitions $(F(6,53)=4.99, p<0.0005$; Fig. 3a), distance traveled $(F(6,53)=6.30, p<0.0001)$, and center entries $(F(6,53)=2.54, p<0.05)$. Furthermore, time $\times$ drug interactions were observed for transitions $(F(30,265)=$ $6.49, p<0.0001)$, distance traveled $(F(30,265)=6.1, p<$ $0.0001)$, and center entries $(F(30,265)=2.6, p<0.0001)$. Tukey's post hoc analyses revealed that $16 \mathrm{mg} / \mathrm{kg}$ GBR 12909 increased transitions and distance traveled when compared with saline for time periods 2-6 and increased center entries for time periods 3-6 $(p<0.05)$. GBR 12909 at $28.5 \mathrm{mg} / \mathrm{kg}$ increased transitions and distance traveled when compared to saline at time periods $2-6 \quad(p<0.05$, although $p<0.1$ for transitions in time period 1) and increased center entries in time periods 3 and 6 only. Increases in transitions and distance traveled were also observed for 13.2 and $10.9 \mathrm{mg} / \mathrm{kg}$ GBR 12909 at time periods 3-6 $(p<0.05)$, while $9 \mathrm{mg} / \mathrm{kg}$ increased transitions and distance traveled in time periods 5 and 6 only $(p<0.05)$. GBR 12909 at $10.9 \mathrm{mg} / \mathrm{kg}$ also increased center entries when compared to saline in time periods 5 and $6(p<0.05)$.

Exploratory behavior For holepoking $(F(6,53)=2.90, p<$ 0.05 ; Fig. 3b) and rearing $(F(6,53)=2.59, p<0.05$; Fig. $3 c)$, significant main effects for drug were observed. Also, time $\times$ drug interactions were observed for holepoking $(F$ $(30,265)=2.0, p<0.005)$ and rearing $(F(30,265)=2.3, p<$ $0.0005)$. No significant effects for center duration were found $(p>0.05)$. Post hoc analyses of significant interactions revealed for rearing that GBR 12909 at 16 and $28.5 \mathrm{mg} / \mathrm{kg}$ induced more rearing when compared to saline in time periods $4-6(p<0.05)$. GBR 12909 at $28.5 \mathrm{mg} / \mathrm{kg}$ increased holepoking in time periods 5 and 6 , while $16 \mathrm{mg} / \mathrm{kg}$ increased holepoking at time period 5, compared to salinetreated mice $(p<0.05)$.

Locomotor patterns A significant main effect of drug was observed for spatial $d(F(6,53)=2.59, p<0.05$; Fig. 3d), and a trend toward a drug $\times$ time interaction was observed $(F(30,265)=1.5, p=0.06)$. Post hoc analyses were performed for the interaction to remain consistent with the rest of the study. Post hoc analyses revealed that GBR 12909 lowered the value of spatial $d$ for doses 10.9, 16, and $28.5 \mathrm{mg} / \mathrm{kg}$ when compared to saline in time periods 2,3 , and 4 , while $13.3 \mathrm{mg} / \mathrm{kg}$ GBR 12909 reduced spatial $d$ in time period 2 only $(p<0.05)$. 


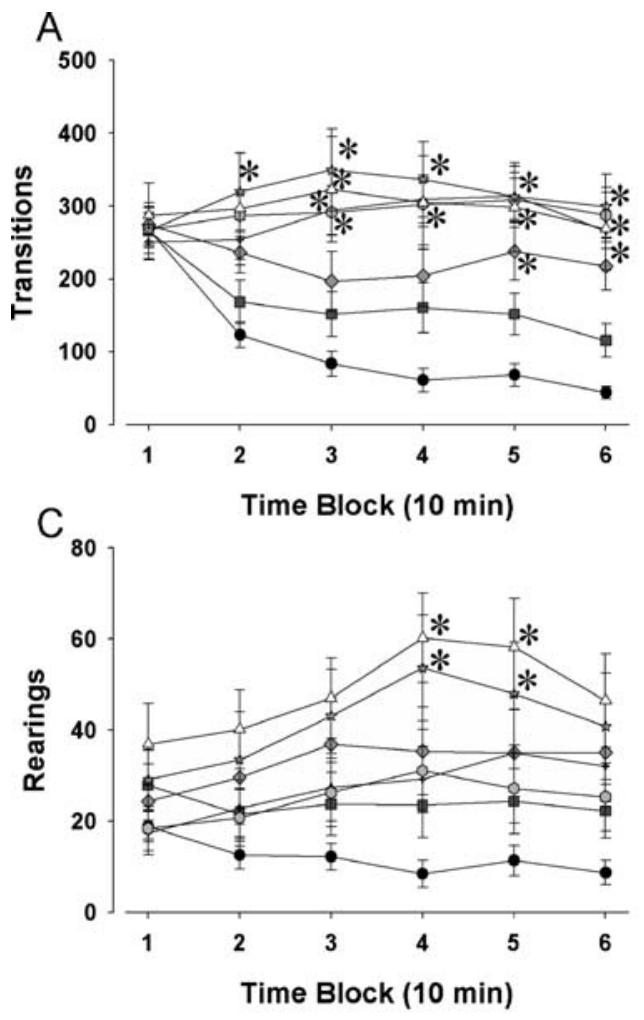

Fig. 3 Effects of GBR 12909 on exploratory behavior in 129/SvJ mice in the mouse BPM. Mice $(129 / \mathrm{SvJ})$ were administered various doses $(5,9,10.9,13.2,16$, and $28.5 \mathrm{mg} / \mathrm{kg})$ of the selective DAT inhibitor GBR 12909 immediately prior to the assessment of their exploration in the mouse BPM. Exploration was measured in the BPM for activity levels - transitions (a), exploration-holepoking (b) and rearing (c), as well as locomotor patterns - spatial $d$ (d). GBR 12909 increased activity at various doses tested, only 16 and $28.5 \mathrm{mg} / \mathrm{kg}$ initially but also $9,10.9$, and $13.2 \mathrm{mg} / \mathrm{kg}$ by the end of testing (a). The

Experiment 4: duration of effect of acute GBR 12909 in $\mathrm{C} 57 \mathrm{BL} / 6 \mathrm{~J}$ mice in the mouse BPM

The duration of effect of GBR 12909 was assessed by administering multiple doses (vehicle, 9,16 , or $28.5 \mathrm{mg} / \mathrm{kg}$ ) to $\mathrm{C} 57 \mathrm{Bl} / 6 \mathrm{~J}$ mice immediately prior to their assessment in the mouse BPM for an extended period of time $(3 \mathrm{~h})$. We hypothesized that GBR 12909 would exhibit long-lasting effects on exploratory behavior.

Locomotor activity Significant main effects of drug were observed for transitions $(F(3,32)=20.4, p<0.0001$; Fig. 4a), distance traveled $(F(3,32)=21.4, p<0.0001)$, and center entries $(F(3,32)=3.2, p<0.05)$. Moreover, time $\times$ drug interactions were observed for transitions $(F$ $(15,160)=3.7, p<0.0001)$, distance traveled $(F(15,160)=$ $4.4, p<0.0001)$, and center entries $(F(15,160)=2.0, p<$ $0.05)$. Tukey's post hoc analyses revealed GBR 12909 at all three doses increased transitions and distance traveled at all six 30-min time intervals $(p<0.05)$, except for $9 \mathrm{mg} /$ $\mathrm{kg}$ at time point $1(p>0.05)$. Increased center entries were
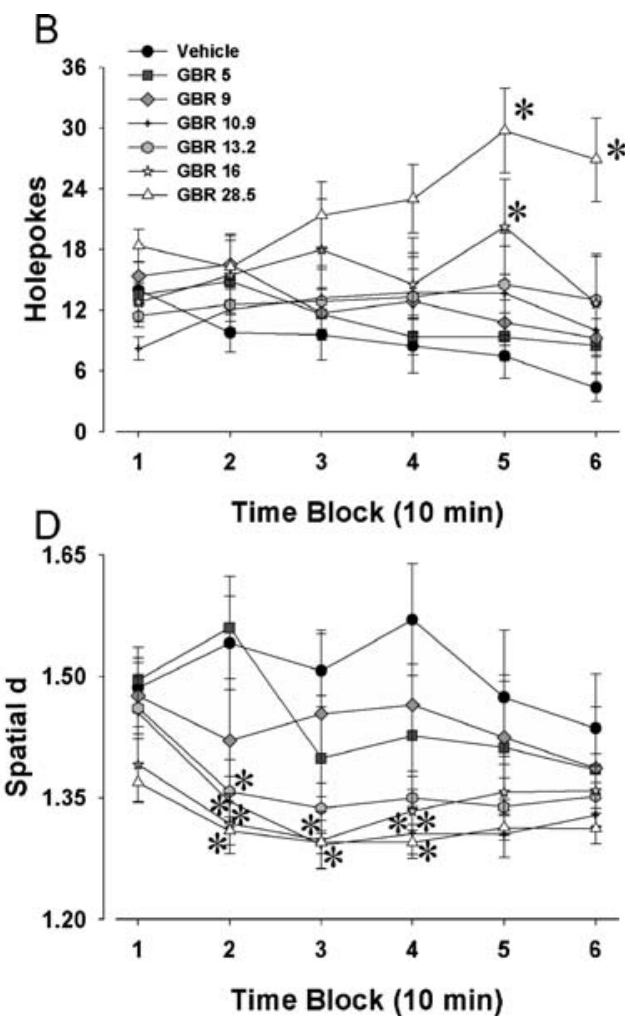

effects of GBR 12909 on exploration were similar for the two measures, with 16 and $28.5 \mathrm{mg} / \mathrm{kg}$ increasing holepoking (b) and rearing (c) toward the end of the test session. Doses of GBR 12909 larger than $10.9 \mathrm{mg} / \mathrm{kg}$ also lowered spatial $d$, although this effect was seen predominantly between 10 and $40 \mathrm{~min}$ (d). Data presented as mean \pm SEM. ${ }^{*} p<0.05$ when compared to vehicle administered control mice. Scales on the $x$-axes differ from Figs. 1 and 2 due to differing basal activity levels of C57BL/6J and 129/SvJ mice

observed following $9 \mathrm{mg} / \mathrm{kg}$ GBR 12909 at time periods 2, 2 , 5, and $6,16 \mathrm{mg} / \mathrm{kg}$ at time periods 3 and 6 , and $28.5 \mathrm{mg} / \mathrm{kg}$ at time period $3(p<0.05)$.

Exploratory behavior No significant main effects of drug were observed for holepoking (Fig. 4b) or center duration, but there was a main effect of drug on rearing $(F(3,32)=$ 5.0, $p<0.01$; Fig. $4 \mathrm{c})$. Time $\times$ drug interactions were observed, however, for holepoking $(F(15,160)=7.1, p<$ $0.0001)$, rearing $(F(15,160)=6.0, p<0.0001)$, and center entries $(F(15,160)=3.1, p<0.0005)$. Post hoc analyses of significant interactions revealed that $16 \mathrm{mg} / \mathrm{kg}$ GBR 12909 increased rearing at 30-min time intervals 3-6, while $9 \mathrm{mg} /$ $\mathrm{kg}$ increased rearing at time periods 3,5 , and 6 and $28.5 \mathrm{mg} / \mathrm{kg}$ increased rearing at time periods 5 and 6 only $(p<0.05)$. While 16 and $28.5 \mathrm{mg} / \mathrm{kg}$ initially decreased poking at time period $1(p<0.05), 16 \mathrm{mg} / \mathrm{kg}$ increased poking at time periods 5 and 6 , while $9 \mathrm{mg} / \mathrm{kg}$ increased poking in the fifth time period $(p<0.05)$. Increased center duration was observed for $9 \mathrm{mg} / \mathrm{kg}$ at time periods 5 and $6(p<0.05)$. 

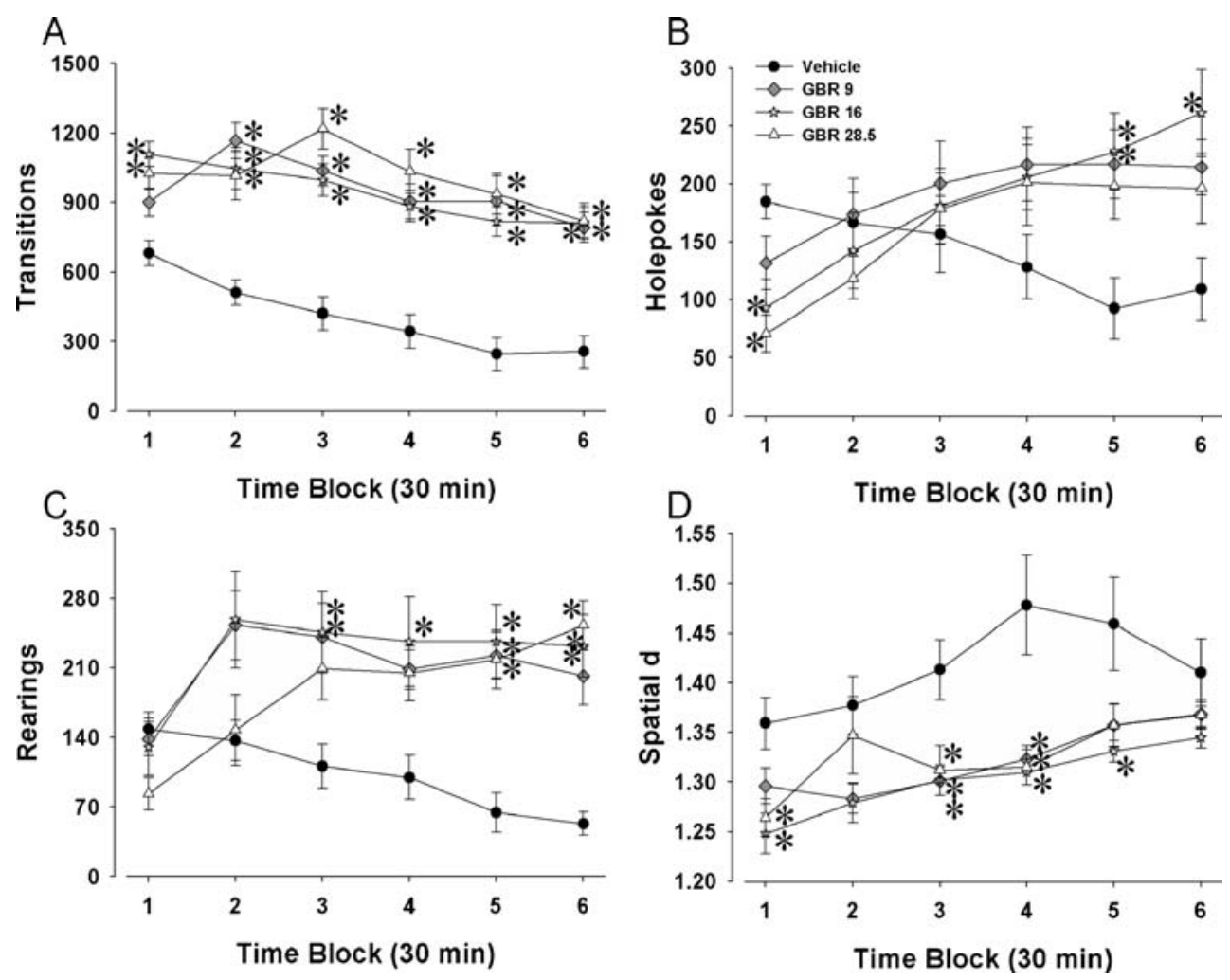

Fig. 4 Time course of the effects of GBR 12909 on exploratory behavior in $\mathrm{C} 57 \mathrm{BL} / 6 \mathrm{~J}$ mice in the mouse BPM. Mice were administered the selective DAT inhibitor GBR 12909 at various doses $(9,16$, and $28.5 \mathrm{mg} / \mathrm{kg})$ immediately prior a 3 -h assessment of their exploration in the mouse BPM. Activity levels - transitions (a), exploration-holepoking (b) and rearing (c), as well as locomotor patterns - spatial $d$ (d) were all measured. GBR 12909 increased

activity at various doses tested, only 16 and $28.5 \mathrm{mg} / \mathrm{kg}$ initially but also $9 \mathrm{mg} / \mathrm{kg}$ throughout the 3-h period (a). Despite an initial drop in holepoking, GBR 12909 at $16 \mathrm{mg} / \mathrm{kg}$ consistently increased holepoking (b) and rearing (c). GBR 12909 at $16 \mathrm{mg} / \mathrm{kg}$ also consistently lowered spatial $d(\mathbf{d})$, with some modest effects at 9 and $28.5 \mathrm{mg} / \mathrm{kg}$ as well. Data presented as mean \pm SEM. ${ }^{*} p<0.05$ when compared to vehicle administered control mice

Locomotor patterns A significant main effect of drug was observed for spatial $d(F(3,32)=6.1, p<0.005$; Fig. $4 \mathrm{~d})$. A time $\times$ drug interaction was also observed for spatial $d(F$ $(15,160)=12.4, p<0.005)$. Post hoc analyses revealed differing effects of drug dose over the 3 -h period. GBR 12909 at $16 \mathrm{mg} / \mathrm{kg}$ reduced spatial $d$ relative to saline at time periods $1,3,4$, and 5 , while $28.5 \mathrm{mg} / \mathrm{kg}$ reduced spatial $d$ only at time periods 1,3 , and 4 and $9 \mathrm{mg} / \mathrm{kg}$ reduced spatial $d$ only at time periods 3 and $4(p<0.05)$.

\section{Discussion}

We investigated the predictive validity of two animal models of quantified hyperexploration in BD mania. These treatment models included the "gold standard" mixed NET/ DAT inhibitor amphetamine and the selective DAT inhibitor GBR 12909. Amphetamine administration induced hyperactivity, as well as reduced spatial $d$ at low doses, consistent with $\mathrm{BD}$ mania patients, with the opposite effect at high

doses. Amphetamine reduced specific exploratory activity at multiple doses, however (Fig. 1), in contrast to manic BD patients in the human BPM (Perry et al. 2009). Mice administered $16 \mathrm{mg} / \mathrm{kg}$ GBR 12909, irrespective of background strain, consistently exhibited increased activity, reduced spatial $d$, and increased exploratory behavior (Fig. 2, 3, and 4). Thus, the phenotype produced by selectively inhibiting DAT function in the mouse BPM was consistent with the behavior of BD patients in the human BPM.

Amphetamine is a relatively nonselective monoamine reuptake inhibitor, being most potent at the NET with 6-10fold less efficacy at DAT in rats, mice, and humans (Han and Gu 2006; Holmes and Rutledge 1976). Although amphetamine treatment has been a popular model with which to assess mania (Einat 2006b; Frey et al. 2006; Gould et al. 2001; Silverstone et al. 1998), the main phenotype of BD modeled has been that of increased motor activity. While lithium has been shown to reduce amphetamine-induced hyperactivity in four out of 12 strains of mice, this effect was observed in doses that also reduced 
activity levels (Gould et al. 2007). Hence, it remains unclear whether lithium specifically ameliorated amphetamine-induced hyperactivity. Here, we demonstrate that while $2.5 \mathrm{mg} / \mathrm{kg}$ amphetamine produced hyperactivity, the higher dose of $10 \mathrm{mg} / \mathrm{kg}$ significantly reduced activity levels presumably due to the induction of competing stereotypies (Fig. 1a). Recent studies providing quantitative assessments of exploratory behavior in manic BD patients have revealed a more complex phenotype, with locomotor hyperactivity being accompanied by increased specific exploratory interactions and reduced spatial $d$ compared to healthy comparison subjects (Perry et al. 2009). While amphetamine administration lowered spatial $d$ at certain doses, it also significantly increased spatial $d$ at the highest dose. The reported effects of amphetamine on specific exploratory behavior have been contradictory, with no effect (Kokkinidis and Zacharko 1980), reduced holepoking/ rearing (File and Wardill 1975; Lister and File 1987), or increased rearing (Gulley et al. 2007; Kim et al. 2000) all being reported. In the present study conducted in the mouse BPM-a direct analog of the human BPM in which the exploratory behavior of $\mathrm{BD}$ patients has been characterized - amphetamine reduced exploratory behavior in contrast to the behavior of manic BD patients (Fig. 1b; Perry et al. 2009). In fact, amphetamine induced a dose-related reduction in specific exploratory activity in the mouse BPM as measured by hole interactions. The combined effect of amphetamine on both NET and DAT is likely to underlie its effect of reducing specific exploration. Manipulation of the norepinephrine system affects exploratory activity (Flicker and Geyer 1982; Kitchigina et al. 1997; Mansour et al. 2003; Sara et al. 1995), with increased norepinephrine in the synaptic cleft-which occurs following NET inhibitionhaving been demonstrated to reduce exploratory behavior of rats in the holeboard task (Sara et al. 1995). An alternative explanation is that reduced specific exploration following amphetamine administration was a result of the development of stereotypic behavior. Although the reduction in activity after administration of amphetamine at $10 \mathrm{mg} / \mathrm{kg}$ was likely due to competing stereotypies, which also resulted in increased spatial $d$ (see Paulus and Geyer 1991), such stereotypy is unlikely to have interfered with specific exploration at low doses $(1.25$ and $2.5 \mathrm{mg} / \mathrm{kg})$. In fact, stereotypy does not appear to affect amphetamine-induced increases in locomotor activity at doses as low as $2 \mathrm{mg} / \mathrm{kg}$ in C57BL/6 mice (Yates et al. 2007). Thus, given that amphetamine inhibits NET and that selective NET inhibition can reduce specific exploration, these data support concerns raised regarding the validity for the amphetamine treatment model of BD in humans (Silverstone et al. 1998), rats (Cappeliez and Moore 1990; Frey et al. 2006), and mice (Arban et al. 2005; Gould et al. 2001). There has been recent interest in the use of the combined amphetamine/ chlordiazepoxide treatment-induced hyperactivity as a model of mania, first described in 1966 (Rushton and Steinberg 1966). Although not assessed in the present study and knowledge of the effects of this model on spatial $d$ and specific exploration are unknown, there is some evidence that low doses of antimanic agents can attenuate this combined model-induced hyperactivity which do not affect activity alone (Arban et al. 2005; Dencker et al. 2008; Vale and Ratcliffe 1987). There is evidence, however, that the observed attenuation of hyperactivity may not be as a result of blockade of the combined drug effects on activity but a chlordiazepoxide-induced potentiation of the hypolocomotor effects of antimanic agents (Arban et al. 2005; Kelly et al. 2009). Thus, it has been suggested that this model may not prove useful in a drug discovery process due to interpretive difficulties (Kelly et al. 2009).

We have demonstrated that more selective inhibition of the DAT through either genetic or pharmacological manipulation did, however, increase exploration in mice as well as inducing hyperactivity and reducing spatial $d$ (Perry et al. 2009). Administration of GBR 12909 induced locomotor hyperactivity consistent with amphetamine (Fig. 5). GBR 12909 at $16 \mathrm{mg} / \mathrm{kg}$ in two background strains led to a hyperactive phenotype that differed from amphetamine but was consistent with previous reports (Kliethermes and Crabbe 2006; Mitchell et al. 2006; van den Buuse and de Jong 1989). Thus, $16 \mathrm{mg} / \mathrm{kg}$ GBR 12909 also reduced spatial $d$ and increased specific exploration (rearing), a phenotype consistent with that of BD patients in the human BPM (Perry et al. 2009). The observed increase in exploration is in concurrence (van den Buuse and de Jong
A

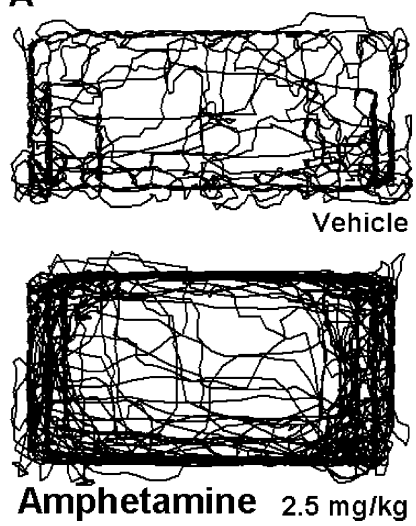

B
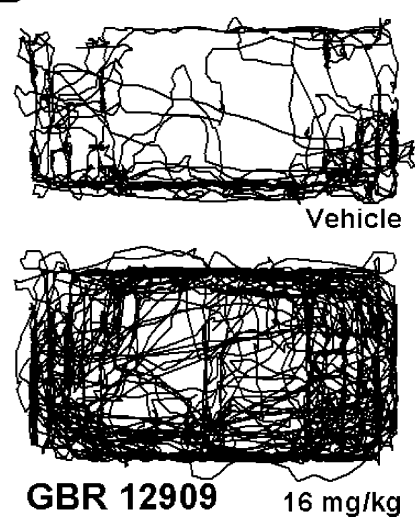

Fig. 5 Representative actigrams from each study. The movement patterns of mice from each study are recorded and analyzed. These figures are representative patterns of movements from mice of each study. Patterns are from the 10-20-min time point of testing. As shown, amphetamine (a) and GBR 12909 administered (b) mice exhibit increased activity levels in the mouse BPM compared to their respective controls. The increased activity also led to more straight distance-covering behavior (lower spatial $d$ ) in these mice 
1989; Zalcman 2001) and in contrast (Kliethermes and Crabbe 2006) with previous reports, although the latter study used WSC rather than C57BL/6J mice as in the present studies and did not examine doses between 10 and $20 \mathrm{mg} / \mathrm{kg}$, where the greatest effects were observed in the present studies. Thus, the data presented here support the selectivity of effects of $16 \mathrm{mg} / \mathrm{kg}$ GBR 12909, with lower doses being less effective and higher doses producing effects consistent with amphetamine. The reduction in specific exploration observed with the highest dose of GBR $12909(28.5 \mathrm{mg} / \mathrm{kg})$ is consistent with the hypothesis that both DAT and NET inhibition reduces exploratory behavior, as observed above with amphetamine. Despite greater selectivity for the DAT, GBR 12909 may inhibit the NET at this dose (Heikkila and Manzino 1984). In support of the DAT-selective phenotype, the present DAT inhibition studies corroborate reports of increased activity and reduced spatial $d$ in mice with reduced DAT levels (Cagniard et al. 2006; Ralph-Williams et al. 2003; Zhuang et al. 2001), as well as adding to observations of increased hole interactions (Perry et al. 2009).

While DAT KD mice exhibited increased holepoking (Perry et al. 2009), GBR 12909 induced increased rearing in C57BL/ $6 \mathrm{~J}$ and 129/SvJ mice. Given that GBR 12909 increased holepoking and rearing in $129 / \mathrm{SvJ}$ mice and increased holepoking in C57BL/6J mice after $150 \mathrm{~min}$ of testing suggests that there is an interaction between GBR 12909 dose and background strain. Previously, strain differences in exploration have been observed in these mice. For example, relative to 129 strains, C57BL/6J mice are notably more active (Paulus et al. 1999) and exhibit baseline differences in these exploratory measures (Rogers et al. 1999; Tang and Sanford 2005). The increased holepoking with time in C57BL/6J mice could also be as a result of the effect of a metabolite of GBR 12909. To our knowledge, the half-life of GBR 12909 has not been studied in mice, however; thus, it is unknown whether GBR 12909 remains active after 150 min, although many studies suggest it has a long half-life in comparison to amphetamine (55 min in mice, 6-9 h in humans; Cho et al. 1973; GBR 12909 equals 48-57 h in humans, Ingwersen et al. 1993; Preti 2000). The present studies demonstrate, however, that by reducing DAT function genetically or pharmacologically resulted in a behavioral profile of increased activity, reduced spatial $d$, and increased specific exploration that mimics that observed in manic BD patients (Perry et al. 2009). Such data may prove useful in guiding future studies investigating the neurobiological basis for BD mania as well as potential treatment options.

Further validation of these models of BD mania is still required, however, such as assessing treatment effects on behavior for example, although given that antimanic treatment does not fully treat BD mania, we would not expect a full reversal of the GBR 12909 phenotype. Further assessment of the cross-species translational validity of the BPM is also required and could include amphetamine administration to healthy patients to ascertain whether the behavioral profile described here following amphetamine treatment in mice would be reproduced in man. This comparison may be particularly relevant given the differences in space availability to test subject ratio for the human and mouse BPMs. Evidence for the suitability of GBR 12909 treatment modeling mania could also be derived from other aspects of behavior relating to $\mathrm{BD}$ as defined by the Diagnostic and Statistical Manual of Mental Disorders, Fourth Edition rating scale, such as aggression, hedonism, hypersexuality, distractibility, reduced sleep (Einat 2006a), inattention (Young et al. 2004, 2009a), working memory (Young et al. 2007a), and executive functioning. For example, given the fact that GBR 12909 produces a longlasting effect on mice in the BPM, it would be feasible to assess its effects on the cognitive performance of mice in tasks that last several hours, such as the attentional set-shifting task (Young et al. 2009b). Other relevant behaviors include reduced sleep, increased reward values, lower anxiety, and hyperactive behavior seen in $\mathrm{BD}$ and also observed in mice carrying a mutation in the Clock gene (Roybal et al. 2007). Since chronic administration of the mood stabilizer lithium attenuated many of these phenotypes, these mutants may also represent a viable animal model of $\mathrm{BD}$. It would be interesting to assess the specific exploratory phenotype of these mice in the mouse BPM, given the quantified exploratory phenotype we have observed in manic BD patients (Perry et al. 2009). Future studies could also investigate the hypothesis that it is the combined effect of amphetamine on DAT and NET that produces a behavioral profile similar, but not fully consistent with manic BD patients. This question could be investigated by combining low-dose GBR 12909 treatment with a selective NET inhibitor such as atomoxetine. Irrespective of future studies, however, the data presented here still provide the first animal model of BD mania that is based on the quantification of exploratory activity in these patients, thus perhaps providing a more precise approach to develop novel therapeutics.

Acknowledgments We thank Richard Sharp, Virginia Masten, Mahálah Buell, and Jordy van Enkhuizen for their support. This study was supported by NIH grants R01-MH071916 and R01-DA002925 and by the Veteran's Administration VISN 22 Mental Illness Research, Education, and Clinical Center.

Open Access This article is distributed under the terms of the Creative Commons Attribution Noncommercial License which permits any noncommercial use, distribution, and reproduction in any medium, provided the original author(s) and source are credited.

\section{References}

Arban R, Maraia G, Brackenborough K, Winyard L, Wilson A, Gerrard P, Large C (2005) Evaluation of the effects of 
lamotrigine, valproate and carbamazepine in a rodent model of mania. Behav Brain Res 158:123-132

Asghar SJ, Tanay VA, Baker GB, Greenshaw A, Silverstone PH (2003) Relationship of plasma amphetamine levels to physiological, subjective, cognitive and biochemical measures in healthy volunteers. Hum Psychopharmacol 18:291-299

Bushnell PJ (1987) Effects of scopolamine on locomotor activity and metabolic rate in mice. Pharmacol Biochem Behav 26:195-198

Cagniard B, Balsam PD, Brunner D, Zhuang X (2006) Mice with chronically elevated dopamine exhibit enhanced motivation, but not learning, for a food reward. Neuropsychopharmacology 31:1362-1370

Cappeliez P, Moore E (1990) Effects of lithium on an amphetamine animal model of bipolar disorder. Prog Neuropsychopharmacol Biol Psychiatry 14:347-358

Cho AK, Hodson BJ, Lindeke B, Miwa GT (1973) Application of quantitative GC-mass spectrometry to study of pharmacokinetics of amphetamine and phentermine. J Pharmacol Sci 62:1491-1494

Collins C, Laird RI, Richards PT, Starmer GA, Weyrauch S (1979) Aspirin-caffeine interaction in the rat. J Pharm Pharmacol 31:611-614

Cryan JF, Slattery DA (2007) Animal models of mood disorders: recent developments. Curr Opin Psychiatry 20:1-7

Dencker D, Dias R, Pedersen ML, Husum H (2008) Effect of the new antiepileptic drug retigabine in a rodent model of mania. Epilepsy Behav 12:49-53

Eilam D, Golani I (1989) Home base behavior of rats (Rattus norvegicus) exploring a novel environment. Behav Brain Res 34:199-211

Einat H (2006a) Establishment of a battery of simple models for facets of bipolar disorder: a practical approach to achieve increased validity, better screening and possible insights into endophenotypes of disease. Behav Genet 37:244-255

Einat $\mathrm{H}$ (2006b) Modelling facets of mania - new directions related to the notion of endophenotypes. J Psychopharmacol 20:714-722

File SE, Wardill AG (1975) Validity of head-dipping as a measure of exploration in a modified hole-board. Psychopharmacologia 44:53-59

Fink JS, Smith GP (1979) Abnormal pattern of amphetamine locomotion after 6-OHDA lesion of anteromedial caudate. Pharmacol Biochem Behav 11:23-30

Fitzgerald RE, Berres M, Schaeppi U (1988) Validation of a photobeam system for assessment of motor activity in rats. Toxicology 49:433-439

Flicker C, Geyer MA (1982) Behavior during hippocampal microinfusions. I. Norepinephrine and diversive exploration. Brain Res 257:79-103

Frey BN, Valvassori SS, Reus GZ, Martins MR, Petronilho FC, Bardini K, Dal-Pizzol F, Kapczinski F, Quevedo J (2006) Effects of lithium and valproate on amphetamine-induced oxidative stress generation in an animal model of mania. J Psychiatry Neurosci 31:326-332

Geyer MA (1990) Approaches to the characterization of drug effects on locomotor activity in rodents. In: Adler MW, Cowan A (eds) Testing and evaluating drugs of abuse. Wiley-Liss, New York

Geyer MA, Markou A (2002) The role of preclinical models in the development of psychotropic drugs. In: Davis KL, Charney D, Coyle JT, Nemeroff C (eds) Neuropsychopharmacology: the fifth generation of progress. Lippincott Williams \& Wilkins, Philadelphia, pp 445-455

Geyer MA, Paulus M (1996) Multivariate analyses of locomotor and investigatory behavior in rodents. In: Ossenkopp KP, Kavaliers M, Sanberg PR (eds) Measuring movement and locomotion: from invertebrates to humans. Landes, Austin, pp 253-271

Geyer MA, Russo PV, Masten VL (1986) Multivariate assessment of locomotor behavior: pharmacological and behavioral analyses. Pharmacol Biochem Behav 25:277-288
Gold LH, Koob GF, Geyer MA (1988) Stimulant and hallucinogenic behavioral profiles of 3, 4-methylenedioxymethamphetamine and N-ethyl-3, 4-methylenedioxyamphetamine in rats. J Pharmacol Exp Ther 247:547-555

Gould TD, Einat H (2007) Animal models of bipolar disorder and mood stabilizer efficacy: a critical need for improvement. Neurosci Biobehav Rev 31:825-831

Gould TD, O'Donnell KC, Picchini AM, Manji HK (2007) Strain differences in lithium attenuation of d-amphetamine-induced hyperlocomotion: a mouse model for the genetics of clinical response to lithium. Neuropsychopharmacology 32:1321-1333

Gould TJ, Keith RA, Bhat RV (2001) Differential sensitivity to lithium's reversal of amphetamine-induced open-field activity in two inbred strains of mice. Behav Brain Res 118:95-105

Greenwood TA, Alexander M, Keck PE, McElroy S, Sadovnick AD, Remick RA, Kelsoe JR (2001) Evidence for linkage disequilibrium between the dopamine transporter and bipolar disorder. Am J Med Genet 105:145-151

Greenwood TA, Schork NJ, Eskin E, Kelsoe JR (2006) Identification of additional variants within the human dopamine transporter gene provides further evidence for an association with bipolar disorder in two independent samples. Mol Psychiatry 11:125133,115

Gulley JM, Everett CV, Zahniser NR (2007) Inbred Lewis and Fischer 344 rat strains differ not only in novelty- and amphetamineinduced behaviors, but also in dopamine transporter activity in vivo. Brain Res 1151:32-45

Han DD, Gu HH (2006) Comparison of the monoamine transporters from human and mouse in their sensitivities to psychostimulant drugs. BMC Pharmacol 6:6

Heikkila RE, Manzino L (1984) Behavioral properties of GBR 12909, GBR 13069 and GBR 13098: specific inhibitors of dopamine uptake. Eur J Pharmacol 103:241-248

Holmes JC, Rutledge CO (1976) Effects of the d- and 1-isomers of amphetamine on uptake, release and catabolism of norepinephrine, dopamine and 5-hydroxytryptamine in several regions of rat brain. Biochem Pharmacol 25:447-451

Horschitz S, Hummerich R, Lau T, Rietschel M, Schloss P (2005) A dopamine transporter mutation associated with bipolar affective disorder causes inhibition of transporter cell surface expression. Mol Psychiatry 10:1104-1109

Ingwersen SH, Snelo S, Mant TGK, Edwards D (1993) Nonlinear multiple-dose pharmacokinetics of the dopamine reuptake inhibitor vanoxerine. J Pharmaceu Sci 82:1164-1166

Kelly MP, Logue SF, Dwyer JM, Beyer CE, Majchrowski H, Cai Z, Liu Z, Adedoyin A, Rosenzweig-Lipson S, Comery TA (2009) The supra-additive hyperactivity caused by an amphetamine-chlordiazepoxide mixture exhibits an inverted-U dose response: negative implications for the use of a model in screening for mood stabilizers. Pharmacol Biochem Behav 92:649-654

Kelsoe JR, Sadovnick AD, Kristbjarnarson H, Bergesch P, Mroczkowski-Parker Z, Drennan M, Rapaport MH, Flodman P, Spence MA, Remick RA (1996) Possible locus for bipolar disorder near the dopamine transporter on chromosome 5. Am J Med Genet 67:533-540

Kim JH, Beeler JA, Vezina P (2000) Group II, but not group I, metabotropic glutamate receptors in the rat nucleus accumbens contribute to amphetamine-induced locomotion. Neuropharmacology 39:1692-1699

Kitchigina V, Vankov A, Harley C, Sara SJ (1997) Novelty-elicited, noradrenaline-dependent enhancement of excitability in the dentate gyrus. Eur J NeuroSci 9:41-47

Kliethermes CL, Crabbe JC (2006) Pharmacological and genetic influences on hole-board behaviors in mice. Pharmacol Biochem Behav 85:57-65 
Kokkinidis L, Zacharko RM (1980) Intracranial self-stimulation in mice using a modified hole-board task: effects of d-amphetamine. Psychopharmacology (Berl) 68:169-171

Kulkarni SK, Dandiya PC (1975) Influence of chemical stimulation of central dopaminergic system on the open field behaviour of rats. Pharmakopsychiatr Neuropsychopharmakol 8:45-50

Lister RG, File SE (1987) The effect of chlordiazepoxide on the habituation of exploration: interactions with the benzodiazepine antagonist RO 15-1788. Pharmacol Biochem Behav 26:631-634

Manji HK, Quiroz JA, Payne JL, Singh J, Lopes BP, Viegas JS, Zarate CA (2003) The underlying neurobiology of bipolar disorder. World Psychiatry 2:136-146

Mansour AA, Babstock DM, Penney JH, Martin GM, McLean JH, Harley CW (2003) Novel objects in a holeboard probe the role of the locus coeruleus in curiosity: support for two modes of attention in the rat. Behav Neurosci 117:621-631

Meliska CJ, Loke WH (1984) Caffeine and nicotine: differential effects on ambulation, rearing and wheelrunning. Pharmacol Biochem Behav 21:871-875

Merikangas KR, Akiskal HS, Angst J, Greenberg PE, Hirschfeld RM, Petukhova M, Kessler RC (2007) Lifetime and 12-month prevalence of bipolar spectrum disorder in the National Comorbidity Survey replication. Arch Gen Psychiatry 64:543-552

Mitchell HA, Ahern TH, Liles LC, Javors MA, Weinshenker D (2006) The effects of norepinephrine transporter inactivation on locomotor activity in mice. Biol Psychiatry 60:1046-1052

Paulus MP, Geyer MA (1991) A scaling approach to find order parameters quantifying the effects of dopaminergic agents on unconditioned motor activity in rats. Prog Neuropsychopharmacol Biol Psychiatry 15:903-919

Paulus MP, Geyer MA (1992) The effects of MDMA and other methylenedioxy-substituted phenylalkylamines on the structure of rat locomotor activity. Neuropsychopharmacology 7:15-31

Paulus MP, Geyer MA (1993) Three independent factors characterize spontaneous rat motor activity. Behav Brain Res 53:11-20

Paulus M, Geyer MA (1996) Assessing the organization of motor behavior: new approaches based on the behavior of complex physical systems. In: Ossenkopp KP, Kavaliers M, Sanberg PR (eds) Measuring movement and locomotion: from invertebrate animals to humans. Chapman \& Hall, New York

Paulus MP, Dulawa SC, Ralph RJ, Geyer MA (1999) Behavioral organization is independent of locomotor activity in 129 and C57 mouse strains. Brain Res 835:27-36

Perry W, Minassian A, Paulus MP, Young JW, Kincaid MJ, Ferguson EJ, Henry BL, Masten VL, Sharp RF, Geyer MA (2009) A reversetranslational study of dysfunctional exploration in psychiatric disorders: from mice to men. Arch Gen Psychiatry 66(10):1045-1054

Preti A (2000) Vanoxerine national institute on drug abuse. Curr Op in Invest Drugs 1:241-251

Ralph-Williams RJ, Paulus MP, Zhuang X, Hen R, Geyer MA (2003) Valproate attenuates hyperactive and perseverative behaviors in mutant mice with a dysregulated dopamine system. Biol Psychiatry 53:352-359

Risbrough VB, Masten VL, Caldwell S, Paulus MP, Low MJ, Geyer MA (2006) Differential contributions of dopamine D(1), D(2), and $\mathrm{D}(3)$ receptors to MDMA-induced effects on locomotor behavior patterns in mice. Neuropsychopharmacology 31:2349-2358

Rogers DC, Jones DN, Nelson PR, Jones CM, Quilter CA, Robinson TL, Hagan JJ (1999) Use of SHIRPA and discriminant analysis to characterise marked differences in the behavioural phenotype of six inbred mouse strains. Behav Brain Res 105:207-217

Rothman RB, Baumann MH (2006) Balance between dopamine and serotonin release modulates behavioral effects of amphetaminetype drugs. Ann N Y Acad Sci 1074:245-260

Roybal K, Theobold D, Graham A, DiNieri JA, Russo SJ, Krishnan V, Chakravarty S, Peevey J, Oehrlein N, Birnbaum S, Vitaterna
MH, Orsulak P, Takahashi JS, Nestler EJ, Carlezon WA Jr, McClung CA (2007) Mania-like behavior induced by disruption of CLOCK. Proc Natl Acad Sci USA 104:6406-6411

Rushton R, Steinberg H (1966) Combined effects of chlordiazepoxide and dexamphetamine on activity of rats in an unfamiliar environment. Nature 211:1312-1313

Sara SJ, Dyon-Laurent C, Herve A (1995) Novelty seeking behavior in the rat is dependent upon the integrity of the noradrenergic system. Brain Res Cogn Brain Res 2:181-187

Sessions GR, Meyerhoff JL, Kant GJ, Koob GF (1980) Effects of lesions of the ventral medial tegmentum on locomotor activity, biogenic amines and responses to amphetamine in rats. Pharmacol Biochem Behav 12:603-608

Shaldivin A, Kaptsan A, Belmaker RH, Einat H, Grisaru N (2001) Transcranial magnetic stimulation in an amphetamine hyperactivity model of mania. Bipolar Disord 3:30-34

Silverstone PH, Pukhovsky A, Rotzinger S (1998) Lithium does not attenuate the effects of D-amphetamine in healthy volunteers. Psychiatry Res 79:219-226

Szechtman H, Ornstein K, Teitelbaum P, Golani I (1985) The morphogenesis of stereotyped behavior induced by the dopamine receptor agonist apomorphine in the laboratory rat. Neuroscience 14:783-798

Tang X, Sanford LD (2005) Home cage activity and activity-based measures of anxiety in 129P3/J, 129X1/SvJ and C57BL/6J mice. Physiol Behav 84:105-115

Vale AL, Ratcliffe F (1987) Effect of lithium administration on rat brain 5-hydroxyindole levels in a possible animal model for mania. Psychopharmacology (Berl) 91:352-355

van den Buuse M, de Jong W (1989) Differential effects of dopaminergic drugs on open-field behavior of spontaneously hypertensive rats and normotensive Wistar-Kyoto rats. J Pharmacol Exp Ther 248:1189-1196

Vawter MP, Freed WJ, Kleinman JE (2000) Neuropathology of bipolar disorder. Biol Psychiatry 48:486-504

Yates JW, Meij JT, Sullivan JR, Richtand NM, Yu L (2007) Bimodal effect of amphetamine on C57BL/6 mice. Neurosci. Lett. 427:66-70

Young LT, Warsh JJ, Kish SJ, Shannak K, Hornykeiwicz O (1994) Reduced brain 5-HT and elevated NE turnover and metabolites in bipolar affective disorder. Biol Psychiatry 35:121-127

Young JW, Finlayson K, Spratt C, Marston HM, Crawford N, Kelly JS, Sharkey J (2004) Nicotine improves sustained attention in mice: evidence for involvement of the alpha7 nicotinic acetylcholine receptor. Neuropsychopharmacology 29: 891-900

Young JW, Kerr LE, Kelly JS, Marston HM, Spratt C, Finlayson K, Sharkey J (2007a) The odour span task: a novel paradigm for assessing working memory in mice. Neuropharmacology 52:634-645

Young JW, Minassian A, Paulus MP, Geyer MA, Perry W (2007b) A reverse-translational approach to bipolar disorder: rodent and human studies in the behavioral pattern monitor. Neurosci Biobehav Rev 31:882-896

Young JW, Light GA, Marston HM, Sharp R, Geyer MA (2009a) The 5-choice continuous performance test: evidence for a translational test of vigilance for mice. PLoS ONE 4:e4227

Young JW, Powell SB, Risbrough V, Marston HM, Geyer MA (2009b) Using the MATRICS to guide development of a preclinical cognitive test battery for research in schizophrenia. Pharmacol Ther 122:150-202

Zalcman SS (2001) Interleukin-2 potentiates novelty- and GBR 12909-induced exploratory activity. Brain Res 899:1-9

Zhuang X, Oosting RS, Jones SR, Gainetdinov RR, Miller GW, Caron MG, Hen R (2001) Hyperactivity and impaired response habituation in hyperdopaminergic mice. Proc Natl Acad Sci USA 98:1982-1987 